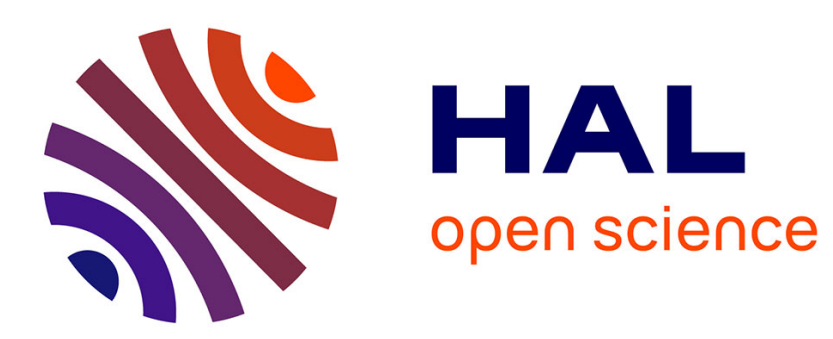

\title{
Public consultations on Net Neutrality 2010: USA, EU and France
}

\author{
Sulan Wong, Julio Rojas-Mora, Eitan Altman
}

\section{To cite this version:}

Sulan Wong, Julio Rojas-Mora, Eitan Altman. Public consultations on Net Neutrality 2010: USA, EU and France. 2010. inria-00523075

\section{HAL Id: inria-00523075 \\ https://hal.inria.fr/inria-00523075}

Preprint submitted on 4 Oct 2010

HAL is a multi-disciplinary open access archive for the deposit and dissemination of scientific research documents, whether they are published or not. The documents may come from teaching and research institutions in France or abroad, or from public or private research centers.
L'archive ouverte pluridisciplinaire HAL, est destinée au dépôt et à la diffusion de documents scientifiques de niveau recherche, publiés ou non, émanant des établissements d'enseignement et de recherche français ou étrangers, des laboratoires publics ou privés. 
INSTITUT NATIONAL DE RECHERCHE EN INFORMATIQUE ET EN AUTOMATIQUE

\title{
Public consultations on Net Neutrality 2010: USA, EU and France
}

\author{
Sulan Wong — Julio Rojas-Mora — Eitan Altman
}

\section{$\mathbf{N}^{\circ} \mathbf{7 4 0 4}$}

Sep 2010

Thème COM 



\title{
Public consultations on Net Neutrality 2010: USA, EU and France
}

\author{
Sulan Wong* , Julio Rojas-Mora ${ }^{\dagger}$, Eitan Altman $^{\ddagger}$ \\ Thème COM — Systèmes communicants \\ Équipe-Projet Maestro
}

Rapport de recherche $n^{\circ} 7404-$ Sep $2010-28$ pages

\begin{abstract}
The evolution of the Internet has come to a point where almost at the same time, governments all around the world feel the need for legislation to regulate the use of the Internet. In preparing the legislation, consultations were called by various governments or by the corresponding regulation bodies. We describe in this paper the various consultations as well as the background related to the Net Neutrality question in each case. Rather than describing the answers to each consultation, which are available and which have already been analyzed, we focus on comparing the consultations and the statistical figures related to the participation in them.
\end{abstract}

Key-words: Net neutrality, Internet Governance, Public Consultation, Network Management, Human Rights, IT Law.

\footnotetext{
* Faculty of Law, Campus of Elviña, University of A Coruña, 15071 A Coruña, Spain. Email: swong@udc.es

${ }^{\dagger}$ Faculty of Economic and Business Sciences, University of Barcelona, o8034 Barcelona, Spain. Email: jrojasmo7@alumnes.ub.edu

₹ Project Maestro, INRIA Sophia-Antipolis, France. Email: eitan.altman@sophia.inria.fr
} 


\section{Des consultations publiques sur la neutralité du Net 2010: USA, UE et la France}

Résumé : Lévolution de l'Internet est arriv à un point où presque simultanément, des gouvernements au tour du globe ont senti le besoin de légiférer pour réguler l'usage de l'Internet. En préparant ces législations, des consultations publiques ont été proposées par les autorités. Nous décrivons dans cet article plusieurs consultations ainsi que les circonstences liées à la question de la Neutralité dans chaque cas. Au lieu de décrir les réponses, déja connues et analysées, nous nous focalisons sur la comparaison entre les consultations et sur les données statistiques qui en sont liées.

Mots-clés : Neutralité du Net, Gouvernance d'Internet, Consultation Publique, Gestion de réseau, Droits de l'Homme, Loi sur les Technologies de l'Information 


\section{Introduction}

2010 has experienced dramatic events related to network neutrality debate. Exceptional legislative initiatives have been taken, which may pave the way to shape a different future for the Internet. We saw the first country, Chile, adopting legislation that establishes network neutrality. Meanwhile, the American Court of Appeals for the District of Columbia Circuit shook the foundation of the net neutrality principle in the USA by denying its telecom regulation body, the Federal Communications Commision (FCC) $)^{1}$, the authority to take decisions and actions on that topic. In preparation to legislation on the topic, public consultations were launched in USA, France and the European Union (EU).

By participating in the effort to answer the French consultation [2], it has been observed that although the issue at stake was particularly important, having a substantial impact on the whole society, the French citizens and media showed little concern about it ${ }^{2}$. An important reason for that is that the consultations on net neutrality are about laws that concerns economic aspects of telecommunications, and that may affect the exercise of fundamental rights. Thus, to be able to have a significant contribution, one needs to have notions in three different fields. Being scholars in these respective three areas, we spent much time in discussions to clarify and understand the main issues of the debate on net neutrality, and to get a complete picture of it. This paper summarizes the findings made through these discussions and the research that followed. While making it, it was surprising to find significant differences between the consultations, even though they deal with the same subject. Through the comparisons between the consultations, new questions raised, and more insight can be gained whenever answers to the questions are available.

Why do we consider the topic important? Network Neutrality touches the heart of the Internet. The Internet has had a huge impact on economy and communication, but also on the exercise of socio-cultural and fundamental rights. What does the Internet represent beyond a jump in technology? In 2009, France passed a law against unauthorized downloading of copyrighted material. Measures against piracy included disconnection from the Internet that could be decided by an administrative decision. The Constitutional Council went back to the Declaration of the Rights of Man and of the Citizen (from the time of the French revolution, two hundred years before Internet's birth) to conclude that the freedom of speech could not be trusted to a new nonjudicial authority in order to protect holders of copyrights and neighboring rights. In its judgement, it recognized that the right to free comunication of ideas and opinions implies the freedom to access the Internet [28, \$12]; in other words, Internet is an instrument for exercising the freedom of speech. Similar relations

\footnotetext{
${ }^{1}$ The FCC is an independent United States government agency established by the Communications Act of 1934, which is charged with regulating interstate and international communications by radio, television, wire, satellite and cable. The jurisdiction covers the 50 states, the District of Columbia and U. S. possesions. See http: //www . fcc.gov/aboutus . html

${ }^{2}$ We can say that the European consultation has been almost invisible in the mainstream media, but we will have to wait for results on its participation.
} 
between the Internet and the American constitution (and amendments) have also been made in the USA ${ }^{3}$. Furthermore, we can see that the Directive 2002/22/EC of the European Union, as amended by the Directive 2009/136/EC, established Internet access as a universal service ${ }^{4}$. The Ministry of Transport and Communication of Finland has passed a Decree in October 2009 that goes beyond the recognition of the right for Internet access: it guarantees the right for broadband Internet connection as a universal service.

There is no agreement on the exact definition of "net neutrality" and, in fact, some of the questions in the French consultation deal with this definition. In general, by neutrality one means in general avoiding unfair discriminating of packet inside the network, in terms of content of the packet, its source or destination, and the protocol or service to which it relates to. Being non-neutral would then mean to discriminate some packets over others in terms of access, pricing, quality of service etc. Some consider as "unfair" any discrimination that is not chosen by the end users. Some others are less restrictive and say that neutrality can exist with different levels of service as long as two users who pay equally, receive the same service and get the same resources ${ }^{5}$. Among the issues that net neutrality is concerned with are relations between access and content providers along with related pricing issues, the possibility of an access provider to have an exclusive agreement with some content provider or some service provider, the possibility to inspect packets and block some of them, and the issue of "proxy censorship" by the ISPs.

In the next section, we describe the governance of the Internet so as to explain the general role of the consultations. This is followed by Sections providing more details on the definition and description of the network neutrality debate, as well as some historical background. Section 5 summarizes the consultations in USA, Europe and France. Some aspects are further expanded in the following section. The paper is finished by a section introducing statistics concerning the responses to the consultation and an analysis of these figures, as well as some conclusions and final remarks.

\section{The governance in Internet}

This section provides three definitions of governance and makes the relation between the governance and the role of the consultations.

The Internet is a global network designed on a set of open standards that allows millions of computers to access a variety of information, communication and electronic commerce services. It has grown in a virtually unregulated environment where a number of private entities, responsible for defining only those matters essential for

\footnotetext{
${ }^{3}$ See $[60]$ for more details

${ }^{4} \mathrm{~A}$ universal service has been defined by the $\mathrm{EU}$, as a service guaranteed by the government to all end users, regardless of their geographical location, at reasonable quality and reliability, and at affordable prices that does not depend on the location.

${ }^{5}$ As we will see in Section 3, Internet protocols that differentiate services and thus allow for different priorities, have been part of the global Internet standards established by the IETF.
} 
its operation and evolution, have exerted the control over its technological progress. For the many stakeholders that carry out their economic and research activity with Internet as their objective, its governance is this control and how it is established by the consensus of the peers that belong to the institutions ${ }^{6}$ that apply it. According to Solum [55], this is a definition of governance in the narrow sense, since it refers to "[Internet's] current operation, and the processes by which it develops and change over time".

Nonetheless, the term "governance", related to activities implemented by national governments or supranational institutions, may have different meanings for different contexts and languages. During the 2003 World Summit on the Information Society (WSIS), many delegations understood it in this sense, which obviously clashed with the narrow sense previously defined. As a matter of fact, it is quite difficult to separate the technological control of Internet with that instituted by governments regulations on any activity carried over its infrastructure. This is what Solum calls the "broad sense" of the Internet governance, one that touches fundamental freedoms and rights like those of speech and privacy, and that is carried out, e.g., in the name of the efficiency of the world economic system, the protection of copyrights, and the combat of terrorism.

There is even a third type of governance action, that in which national and supranational government institutions require the direct participation of the civil society and stakeholders through the process of public consultation. The aim is to develop regulatory frameworks that are more closely related to the needs and opinions of the participants. According to the EU Commission [12, p. 4], "consultation is intended to provide opportunities for input from representatives of regional and local

${ }^{6}$ The main institutions for Internet's governance are:

1. The Internet Society (ISOC), an international, nonprofit organization that supports Internet's growth and development, born from the need to protect, from legal liability for intellectual property infringement, the individual researchers that were part of the standard definition process.

2. The Internet Engineering Task Force (IETF), officially part of the ISOC, is a volunteer composed, standard definition organization that designs the protocols that make up the TCP/IP suite. A "Request for Comments" (RFC), a document produced through the consensus of a working group devoted to some issue, defines an IETF standard.

3. The Internet Corporation for Assigned Names and Numbers (ICANN), a nonprofit corporation that is in charge of the assignment of IP addresses and domain names. The international community has discussed ICANN's work, rejecting the position of the U.S. government by not allowing that the United Nations could manage it through the Internet Governance Forum.

4. The World Wide Web Consortium $\left(\mathrm{W}_{3} \mathrm{C}\right)$, the organization in charge of developing standards for web services. It differs from the IETF in that the director position is not elected, making Tim Berners-Lee its perpetual director. Working groups keep all $\mathrm{W}_{3} \mathrm{C}$ standards secret until their final release.

5. The Institute of Electrical and Electronic Engineers (IEEE), a professional association that has been a key player in defining telecommunications standards that allow devices to connect to the Internet.

For more information see [7]. 
authorities, civil society organisations, undertakings and associations of undertakings, the individual citizens concerned, academics and technical experts, and interested parties in third countries." As a matter of fact, the European Union, through the Treaty of Lisbon, orders the Commission to "carry out broad consultations with parties concerned in order to ensure that the Union's actions are coherent and transparent" [23, Art. 8(B)(3)]. The United States' agencies like, the FCC, are ordered by law to "give interested persons an opportunity to participate in the rule making through submission of written data, views, or arguments with or without opportunity for oral presentation" [1, Title 5, \$553 (c)].

Estévez Araujo [18] explains that the rhetoric of the governance presents the public consultation process as a rational discussion, firstly, between stakeholders and, secondly, between stakeholders and the authorities. This debate tries that the differences of positions evolve, from being factors that give rise to stalemates, to be elements of debate enrichment. Nevertheless, he concludes that due to the inherent characteristics of the governance process, neither popular participation nor social transformation are its main objectives, but only negotiation and problem resolution for stakeholders. The language used in the public consultations documents, as well as the knowledge needed to answer them, narrows the scope for participation to only those stakeholders fully dedicated to the subject in debate: scientific researchers, industry stakeholders and lobbies, and non-governmental organizations (NGOs). In section 5, we will see specific details on this subject in the net neutrality public consultation documents.

In a general context, the European Commission joins these three points of views defining governance as the "rules, processes and behavior that affect the way in which powers are exercised at European level, particularly as regards openness, participation, accountability, effectiveness and coherence" [11, p. 8]. In the case of the Internet governance, the WSIS defined it as "development and application by gouvernments, the private sector and civil society, in their respective roles, of shared principles, norms, rules, decision-making procedures, and programmes that shape the evolution and use of the Internet" $\left[61, \$_{34}\right]$.

\section{On the definition of "Net Neutrality"}

For Hahn and Wallsten[35] net neutrality "usually means that broadband service providers charge consumers only once for Internet access, do not favor one content provider over another, and do not charge content providers for sending information over broadband lines to end users". Nonetheless, this definition is far from being a standard and has evolved together with the Internet from being a purely technical issue to be a content related one.

One of the of the main tenants theoretically enshrined by the narrow sense of the Internet governance, a guide in the design of its architecture [9], is the "endto-end principle" [51]. This principle calls for any intelligence to be implemented below the transport layer only if it cannot be implemented effectively in higher layers; 
intelligence is pushed, thus, to the edges of the network. As the processing needed to forward data packets between network elements is minimal, the network becomes relatively simple and only a "best effort" service is provided. This kind of service does not provide any guarantees on delivery rates, as all packets going through the network will have the same priority and, in case of congestion, the same probability of being dropped. The "net neutrality" principle is firstly based on this behavior, as there is no discrimination between data flows and no quality of service (QoS) level can be guaranteed. We will call this view the "technical sense" of the net neutrality principle.

However, the technical sense of the net neutrality was quickly undermined by the design of real-time services, which require to have priority over other types of traffic in order to guarantee QoS. The Integrated Services model (IntServ) was designed to allow for QoS on particular services as well as to control the proportion of a link's bandwidth assigned to each service type [6]. IntServ was designed to be a rich but complex protocol to guarantee QoS, leaving a "clear need for relatively simple and coarse methods of providing differentiated classes of service for Internet traffic, to support various types of applications, and specific business requirements" [10]; these methods were called the Differential Services enhancements (DiffServ) and were defined in the RFCs 2474 and 2475 [47, 4]. The changes were so big that not only the architectural principles had to change, but also the language used in terms of service needed to do it accordingly [33].

Even if perpetuated by the idea that ISPs yield too much power to be trusted with the task of performing a "fair discrimination", Hahn and Litan [34] believe that "net neutrality", in the technical sense, is a myth. In the light of the deployment of more intelligent networks, capable of automatically prioritize data for applications that critically need it, this myth becomes even more clear. These networks allow the development of many services whose suppliers would be willing to pay more for the ability to provide them in optimal conditions, subsidizing, then, the services that get satisfied with the "best effort" guarantee. Nevertheless, the idea of a two-tier Internet carries with it the possibility of leaving the lowest level under such conditions that new entrepreneurs will not be able to compete with those in the highest level. Therefore, success bestows not the best service, but the service that gets into the highest level, under the best possible deal with its ISP [63].

A second view of net neutrality, the one we will call the "content sense" of the net neutrality, relates to the fact that ISPs cannot favor some CP over its competitors, due to some signed agreement that might even be of exclusivity. Internet users connected through any ISP are free to choose the contents they require from the CP they like the most from the whole set of CPs available in Internet, and not from a subset handpicked by the operator. We can see that ISPs will be able to setup their networks to force some CP service into their subscribers, using the same tools given to them to discriminate traffic according to priority and QoS concerns.

Building on the third kind of governance, national and supranational gouvernments are trying to control the problem emerged with the debate on the "network neutrality". The US government, through the FCC [25], has been the first government 
to tap on the knowledge of the "general public" to resolve this debate, quickly followed by the French government [29] and the European Commission [15]. Nonetheless, the eyes of the world are, as FCC Commissioner's Robert M. McDowell recognized, all over the steps taken by his agency:

"I was reminded how closely the international community watches the FCC's movements. After I spoke with regulators from other nations, it became obvious to me that some countries are waiting for the U.S. to assert more government authority over the Internet to help justify an increased state role over Internet management internationally. It is not an exaggeration to say the world is watching what we do. Although we are proceeding with the best of intentions, as we examine the important issues raised in today's Notice, we should keep in mind that our final actions inadvertently could be setting a precedent for some foreign gouvernments with less pure motives to use in justifying stricter Internet regulation. That would be a mistake. Freedom is best served if we promote abundance, collaboration and competition over regulation and rationing. No government has ever succeeded in mandating innovation and investment" [26, pp. $96-101]$.

For Neelie Kroes, the Commissioner for the Digital Agenda, any solution to the net neutrality debate has to take into consideration the respect for the freedom of expression, the transparency of the practices used by operators, the promotion of infrastructure investment as a way to fight "monopolistic gatekeepers", the protection of the fair competition principle for all stakeholders in the value chain, and the promotion of innovative business models in Internet [38].

\section{Historical background of the debate}

\subsection{USA}

It is in the USA that the open and neutral Internet started, and it is natural that it was there that the debate on neutrality began. At least since 2002, we find references to the debate on net neutrality, when a group of the largest American technology and ecommerce companies joined in asking the FCC to "ensure that transmission network operators do not encumber relationships between their customers and destinations on the network" [42]. However, already in 200o, Lemley and Lessig warned of the attack at the end-to-end principle by the large broadband providers wishing to offer bundled services: "...ISPs would have the power to discriminate in the choice of Internet services they allow, and customers who want broadband access would have to accept that choice" [39].

It was in 2003 that the term "net neutrality" was coined by one of the leading researchers in the subject, Tim $\mathrm{Wu}$ [62]. For Wu, network neutrality means that the ISP does not favor one application over another, leaving the choice to users, who will 
use meritocratic arguments to justify their decision. Success in the Internet world, thus, becomes a Darwinian subject, as only the fittest survives.

Asked in 2005 about the new Internet services success, then SBC, and later AT\&T, CEO Edward Whitacre exposed the position of the broadband industry [48]:

"How do you think they're going to get to customers? Through a broadband pipe. Cable companies have them. We have them. Now what they would like to do is use my pipes free, but I ain't going to let them do that because we have spent this capital and we have to have a return on it. So there's going to have to be some mechanism for these people who use these pipes to pay for the portion they're using. Why should they be allowed to use my pipes? The Internet can't be free in that sense, because we and the cable companies have made an investment and for a Google or Yahoo! or Vonage or anybody to expect to use these pipes [for] free is nuts!".

Comments like this generated replicas from those who later became the standard bearers of the pro-neutrality movement, such as Michael Geist, who since 2005 have expressed concerns over the interest of ISPs to create a two-tier Internet [30].

The net neutrality debate permeated into politics, specially in the U.S., during Barack Obama's term as senator.(2005-2008), as two bills that he cosponsored, supporting net neutrality, were not finally approved $[54,16]$. However, Obama made one of his presidential campaign promises to get statutory protection of net neutrality.

The biggest legal case in the net neutrality debate started in 2007, when a group of users of the U.S. broadband provider Comcast, found that downloads made using $\mathrm{P}_{2} \mathrm{P}$ networks were filtered and throttled. NGOs Free Press and Public Knowledge, among others, introduced a complaint with the FCC for Comcast's violation of the "Internet Policy Statements" set forth in [24]. Comcast expressed that it needed to implement these traffic management policies to limit the congestion that $\mathrm{P}_{2} \mathrm{P}$ traffic generated. Supporting neutrality, the FCC ruled that ISPs can not discriminate arbitrarily between types of traffic, causing that Comcast demanded a judicial review of this decision. The Court of Appeals for the District of Columbia Circuit finally ruled that the FCC had no legal authority to sanction discriminatory practices of Internet traffic [58].

Julius Genachowski, Chairman of the FCC, issued a statement in May 2010, in which he expressed the Commission was going to look for a "third way" to solve the net neutrality debate in the USA [31]. This solution will "recognize the transmission component of broadband access service-and only this component-as a telecommunications service", while forbearing from "application of the many sections of the Communications Act that are unnecessary and inappropriate for broadband access service". Inmediately, a group of 72 congressmen answered Genachoski' statement with a letter in which they express "serious concerns about the proposed new regulatory framework". For them, the proposal will cause both, a controversy that will be distracting from what they see should be the main communications priority, "getting every American online", and uncertainty that "will jeopardize jobs and deter needed 
investment for years to come" [32]. They urged Genachowski not to take any step towards reclassification of the broadband service "without additional direction from Congress". In answer, Senator John Kerry asked the FCC to act on his own as there is a "Congressional stalemate" on the issue that will make the "legislative solution increasingly unlikely in the near term", leaving Genachoswki's "third way" as the "only real option to maintain the proper role of government oversight in communications" [45].

\subsection{Europe}

Meanwhile, in July 2006, the European Commission launched a consultation on online content for "promoting fast and efficient implementation of new business models for the creation and circulation of European content and knowledge online" [13]. Question 20 of this consultation refers, in what appears to be officially the first time for the European Union, to the principle of net neutrality and the position respondents had on it.

During a conference on net neutrality made in 2008 in Copenhagen, the then Commissioner for Information Society and Media, Viviane Reding, acknowledged that unlike in the U.S., in Europe the debate on net neutrality had not aroused such media coverage [49]. However, as the discussion of the reform of the telecommunications directives was held at that time, pro-neutrality lobbyists asked to incorporate the principles of protection of net neutrality in them. Reding clearly stated that although the Commission recognized the importance of the principle of neutrality to ensure that the CPs could offer innovative services and that consumers could access the services of their choice, it was also true that the European regulation allowed traffic management as a tool for providers to experiment with different offerings to their customers. However, the Commissioner concluded that traffic management would be controlled by both, the European Commission as well as national gouvernments, to avoid offerings with unacceptably low levels of quality.

\subsection{France}

In mid-2009, a section on network neutrality appears in the official magazine of the French regulatory agency ARCEP, which includes not only an informative article on the situation, but also the views of spokesmen from different stakeholders. Christopher Boam, director of regulatory affairs for Verizon, expressed through this outlet [5] that even if for his company Internet should remain "open" and "neutral", this does not mean that all bits are equal, being necessary to use traffic management techniques for some applications. Boam recognized that this might lead to abuses, but the problems generated by the use of traffic management technologies should be evaluated on a case by case basis, instead of establishing net neutrality legislation.

The French government did not adopt any explicit position before or during the consultation concerning neutrality. In particular, in the questionaire of the French consultation there is no clear position with respect to the neutrality question, 
yet there are many indications that the French authorities are not at all in favor of neutrality. Indeed, while the public consultation was running, the ARCEP organized a conference in April 2010 in which Jean-Ludovic Silicani, its president and editor of the conclusions, expressed that the "government" of the Internet should not be left to a "club" of Anglo-Saxon private actors [3, p. 117].

In addition, the so-called "Zelnick Report" [64], which came out in January 2010, proposed to impose a tax on advertising revenue generated by the use of online services from France. According to estimates put forward by the authors, between 10 to 20 million euros would be collected mainly from U.S. content providers (Google, Microsoft, AOL, Yahoo and Facebook). It is pertinent to note that the report expresses concerns about the drop in advertising revenues of the French content providers, citing the poor state of competition in the French market for search engines, and certain behaviors -never clarified in the text- of Google. Later, French President Nicolas Sarkozy supported this proposal in a speech where he presented a set of policies to support the sector of cultural content creation [53]. Note that this position of the French president is not mentioned in the document overview which is part of the questionaire of the French consultation.

\section{Brief background on the public consultations}

We introduce below each one of the three consultation, their structure and the main objectives that seem to be guiding them. Some related statistics are provided.

\subsection{The Consultation in the USA}

By the end of 2009 and for a period of five months ${ }^{7}$, the FCC presented the general public with a Notice of Proposed Rulemaking (NPRM) [25] for "Preserving the Open Internet Broadband Industry Practices". In principle, it was addressed to codify, into obligations for broadband Internet access service providers, the four principles ${ }^{8}$ that the FCC previously adopted to ensure the openness of broadband networks [24]. Two

\footnotetext{
${ }^{7}$ However, for the Comissioner Robert M. McDowell [25, p. 101], a longer time frame was needed due to the "complicated and highly technical" issues included in the NPRM, as well as "to receive guidance from the court on [their] legal authority to proceed as may be decided in the Comcast/BitTorrent appeal".

${ }^{8}$ This principles are:

- To encourage broadband deployment and preserve and promote the open and interconnected nature of the public Internet, the consumers are entitled to access the lawful Internet content of their choice.

- To encourage broadband deployment and preserve and promote the open and interconnected nature of the public Internet, the consumers are entitled to run applications and use services of their choice, subject to the needs of law enforcement.

- To encourage broadband deployment and preserve and promote the open and interconnected nature of the public Internet, the consumers are entitled to connect their choice of legal devices that do not harm the network.
} 
new principles were also included, those of "non discrimination" of any "lawful" content, application and service, and "transparency" of "network management and other practices as is reasonably required [...] to enjoy the protections specified in this rulemaking" [25, \$16]. The aim was clarifying in this way who and how must comply with them, since for the FCC, leaving them as principles limited its enforceability. These obligations are subject to "reasonable network management", although they "would not supersede" emergency situations or needs from public authorities.

The FCC also looked for comments on how, in what phases and to what extent these obligations should apply to wireless services, like mobile, unlicensed, fixed, and satellite communication systems. It asks, too, for comments to assess if the proposed obligations should also apply to the so called "managed" or "specialized" services ${ }^{10}$, entirely or only in part. Finally, the Commission would like to know the "enforcement procedures" needed to let it ensure compliance between broadband service providers.

\subsection{The European Consultation}

In a parallel process in Europe, during the discussion of the Telecom Package ${ }^{11}$, the net neutrality debate emerged thanks to news about web sites blocking and Internet services throttling, a clear indication that ISPs were trying to discriminate Internet traffic based on source, destination or content [15]. The European Comission adopted in this context a Declaration on Net Neutrality, in which the importance of preserving the open and neutral character of Internet is recognized as a policy objective as well as a regulatory principle. This institution commits itself to monitor the impact on "net freedoms" - "the ability of end-users ${ }^{12}$ to access and distribute information or run applications and services of their choice"13-, by market and technological developments [14]. As its flagship on the subject, the Commission has issued a public consultation [15] focused on the ISPs' behavior regarding the "network management"

- To encourage broadband deployment and preserve and promote the open and interconnected nature of the public Internet, the consumers are entitled to competition among network providers, application and service providers, and content provider.

${ }^{9}$ The FCC remarks that the word "lawful" leaves it clear that nothing requires that ISPs allow users to engage in unlawful activities $[25, \$ 96]$. Access providers will be allowed to take reasonable measures to cope with unlawful distribution of digital contents $[25, \$ 135,139]$.

${ }^{10}$ Essentially voice and video services not previously classified and that might spur both, competition on this market as well as deployment of broadband networks. See [25, IV.G].

${ }^{11}$ The set of directives (Framework Directive, Access Directive, Authorisation Directive, Universal Service Directive and e-Privacy Directive) governing telecommunications in the European Union. The new legislative measures stated in the Directives 2009/136/CE and 2009/140/CE must be incorporated into the legal framework of each Member State of the European Union, who also must publish the new laws, regulations and administrative provisions by May 25, 2011. See [21, Art. 4], [22, Art. 5].

12 "End-Users" are defined by the EU as users "not providing public communications networks or publicly available electronic communications services." [20, art. 2 (h)]

${ }^{13}$ This new provision that has been included in article 8 of the amended telecommunications Framework Directive, seems to be a synthesis drawn from the first two regulatory principles of the FCC for an open Internet [24]. 
or "traffic management" policies, as differential treatment of Internet traffic can undermine the social and economic benefits the Internet's openness has provided. The Comission plans to add the results of these activities, including the findings of the public consultation, in its annual report to the Parliament and the Council.

\subsection{The French Consultation}

On its own, the French government launched a public consultation process on net neutrality [29]. To the questions already raised about intelligent traffic administration, the French consultation, like the American, touches the subject of unlawful traffic. The document states that there might be some illegal activities over Internet that might require its blocking or filtering, generating the need to assess the impact of such practices on Internet's operation. According to the text, the net neutrality principle is not incompatible with the application of the law in the realm of Internet, as it seeks the preservation of the public order.

The consultation also recognizes the growing tension between the stakeholders involved in the chain of value, arising from an increased demand for services due to the popularity of social networking and multimedia applications. This phenomenon may lead, in some cases, to sites and routes with a high concentration of users that alter the "mapping of flows". The congestion generated in these routes affects the performance of a network that has to guarantee QoS, requiring either or both, investment in infrastructure and traffic management policies to solve the problem. How to recoup these investments and if the implemented policies lead to flow differentiation, as well as to the fragmentation of the Internet, are two of the main topics to be discussed.

\section{Issues in the core of the consultations}

\subsection{Free, open and neutral Internet}

The policies adopted by the FCC to guarantee "that broadband networks are widely deployed, open, affordable, and accessible to all consumers" have followed, since 2005, the four principles that for it defines an open Internet. These principles, that have guided the ISPs in their relationship with their customers and that have balanced the different interests among stakeholders -consumers, broadband service providers, application and content providers and technology companies ${ }^{14}$-, are now formulated in the NPRM as obligations for the ISPs. Its the opinion of the FCC that the general shape in which these principles were formulated is kept, only now there is a clear view on who is the subject of statutory obligation, and to whom it is required to fulfill a certain behavior. Thus, ISPs have the duty to comply with the following specific rules:

${ }^{14}$ See note 203 of [25]. 
- Subject to reasonable network management, a provider of broadband Internet access service may not prevent any of its users from sending or receiving the lawful content of the user's choice over the Internet.

- Subject to reasonable network management, a provider of broadband Internet access service may not prevent any of its users from running the lawful applications or using the lawful services of the user's choice.

- Subject to reasonable network management, a provider of broadband Internet access service may not prevent any of its users from connecting to and using on its network the user's choice of lawful devices that do not harm the network.

- Subject to reasonable network management, a provider of broadband Internet access service may not deprive any of its users of the user's entitlement to competition among network providers, application providers, service providers, and content providers.

Two additional obligations were also codified in the NPRM:

- Subject to reasonable network management, a provider of broadband Internet access service must treat lawful content, applications, and services in a nondiscriminatory manner.

- Subject to reasonable network management, a provider of broadband Internet access service must disclose such information concerning network management and other practices as is reasonably required for users and content, application, and service providers to enjoy the protections specified in this part.

The FCC believes these obligations will provide the best tool to protect consumers from abussive practices and to promote both competition for Internet access and content [25, \$52], as well as "investment and innovation with respect to the Internet, as with other communications technologies" $\left[25, \$_{51}\right]$. The objective is to ensure that users can select any offering available to them, and not only those handpicked by their ISPs [25, \$94]. Based on these six obligations, the FCC, through its NPRM, sought comments on the best means to ensure an open Internet, in such a way that they "protect the legitimate needs of consumers, broadband service providers, entrepreneurs, investors, and businesses of all sizes that make use of the Internet" $[25, \$ 10]$.

The European consultation adds, as an annex, the Declaration on Net Neutrality of the European Comission [14], which holds the importance of keeping Internet open and neutral. Given that European authorities seem to hold net neutrality in high steem, the consultation asks if, actually, there are problems with net neutrality and the openness of Internet in Europe. For them, and in the consultation document, the Internet is "open" when it allows "end users in general to access and distribute information or run applications of their choice" $[14$, p. 2]. In this way, the document 
separates "neutrality", which implies non-discrimination, from "openness", to which the "net freedoms" of citizens are related; the "openness" affects end users, while the "neutrality" affects operators, although discrimination between operators eventually ends up affecting the ability of end users to access the Internet and what it represents ${ }^{15}$. However, in the text we can see that neutrality and openness are concepts that are sometimes used interchangeably ${ }^{16}$.

On the subject of an "open", "neutral" or "free" Internet, the French consultation merely refers to the principles established by the FCC; notwithstanding, these principles that define an "open" Internet in the American consultation, are used to define a "neutral" Internet in the French one. On a second level, the concept of "net neutrality" is also shown as a mixture of both, what we have called the technical and the content senses. However, in a bit redundant way, the concept of "non-discrimination" is detached from that of "neutrality"17 while explaining that peering agreements should be rethought. Obviously, "non-discrimination" as a principle was brought from the NPRM [43, p. 7], which does not have "neutrality" as a goal; therefore, while the "non-discrimination" principle is not redundant at all in the NPRM, in the French consultation, that uses the concept of "neutrality", it seems to be. Finally, the short length of this document has not allowed the French government to include the variety and number of references on the openness and neutrality of the Internet that the FCC does. Maybe this is evidence that the debate on this issue has not yet matured in France and that, perhaps, this initiative obeys reasons that we will discuss later.

\subsection{Traffic management on the net}

The consultations agree that traffic management is emerging as one of the most delicate points in the debate over net neutrality, as the ISPs have pushed to be allowed to discriminate traffic in a more active way ${ }^{18}$, due to the high rate at which Internet traffic is growing ${ }^{19}$. The alternative to traffic management, to address congestion problems, is the investment in network infrastructure. However, the consultations

\footnotetext{
${ }^{15}$ Stéphane Richard, COO of France Telecom, has expressed that his organization supports the concept of an open Internet, where many actors have a responsibility to ensure this character, over the concept of a neutral Internet, in which ISPs are solely responsible for preventing discrimination of data streams. See http: //www . arcep.fr/index.php?id=10411.

16 “.... a number of cases have emerged involving the differentiated treatement by network operators of services or traffic which have led some interested parties to question whether the principle of the openness or neutrality of the Internet may be at risk" [15, p. 5].

${ }^{17}$ “... la necesité de préserver les conditions d’un access ouvert, neutre e non-discriminatoire á Internet pour éviter de figer les positions dominantes de certains acteurs" [43, p. 5].

${ }^{18}$ Even though the FCC recognizes that ISPs have been "blocking or degrading Internet traffic" [25, §5].

${ }^{19}$ The traffic shapping software vendor Sandvine explaines that "[b]andwidth intensive applications are appearing at a rate faster than capacity can be added to the last mile of networks" and "[a]pplying traffic management principles levels the playing field for all by alleviating network congestion and ensuring that a limited resource is fairly shared by all users" [52, pp. 1, 7]. As a matter of fact, if the report made by Nemertes Research is believed, at this moment we should be in the middle of a global congestion crisis [46].
} 
also agree ${ }^{20}$ to reflect the concern of operators about the possibility of recovering this investment without providing differentiated services on the Internet $[27,44]$. From the point of view of the law, both approaches to solving congestion -traffic management and provision of differentiated services-, converge in the same problematic situation, as both of them interfere with the exercise of fundamental rights and freedoms by controlling the contents or applications that run on the network.

\subsubsection{Reasonable network management}

In the NPRM $[25, \$ 16]$, the FCC emphasizes that the obligations required of the ISPs are subject to "reasonable network management", although they "would not supersede" emergency situations or needs from public authorities, consistent with applicable law. It is unclear from the text what is for the FCC "reasonable network management", even though there is a the vague, confusing and rather circular definition:

"Reasonable network management consists of: (a) reasonable practices employed by a provider of broadband Internet access service to (i) reduce or mitigate the effects of congestion on its network or to address quality-of-service concerns; (ii) address traffic that is unwanted by users or harmful; (iii) prevent the transfer of unlawful content; or (iv) prevent the unlawful transfer of content; and (b) other reasonable network management practices" [25, \$135].

In defining what sets a reasonable management policy, the FCC recognizes deviating from a guideline previously used that considered "reasonable" those practices which "should further a critically important interest and be narrowly or carefully tailored to serve that interest" $[25, \$ 137]$. This guideline appears as unnecessarily restrictive to the eyes of the Commission, given the flexibility needed to establish what becomes "reasonable" in light of the non-discrimination obligation.

This decision seems to go in the opposite direction of Canada's Telecom Regulatory Policy $[8, \$ 43]$, the product of a public consultation. When answering a complaint on traffic management, an ISP must describe the practices employed, as well as its need, purpose and effect, identifying whether the practice results in discrimination or preference. If so, the ISP must demonstrate that the practice was designed to address and solve the effect in question, "and nothing else." The collateral damage to others and resulting discrimination or preference, must be as little as possible. Finally, the provider must justify why infrastructure investment is not a reasonable alternative to the implementation of such practices. When these practices are lead to blocking traffic, they cannot be implemented without the approval of the CRTC $^{21}$, which will ensure to grant it only when they further the objectives set out in the Canadian Telecommunications Act [8, \$122].

In the case of wireless networks $[25, \$ 172]$, the FCC understands that the definition of what constitutes reasonable management practices is even more complex. The

\footnotetext{
${ }^{20}$ See $[25, \$ 80],[43$, p. 4], [15, p. 8].

${ }^{21}$ Canadian Radio-Television and Telecommunications Commission.
} 
Commission recognizes that certain "rules of the road" are critical to maximize the performance of the limited spectrum each operator has. It seems that service providers in wireless environments will have an even greater leeway, with respect to the definition of "reasonable". The "rules of the road" would not only be established in a completely arbitrary way for each particular provider, but they may also change in real time, given certain patterns of use that each ISP assesses differently.

\subsubsection{The interference in the exercise of fundamental rights}

The American consultation delves on the interference in the exercise of the freedom of speech and civic participation, when operators apply techniques for traffic management. The ISPs could use their traffic management policies to block, slowing or redirecting access to sites that they might consider contrary to their interests, and that they might also inspect email messages, filtering them according to their contents [25, \$75]. Furthermore, the use of Deep Packet Inspection (DPI) techniques as the most intelligent measure for traffic discrimination clearly threatens the right to communications privacy.

As we have already seen, the NPRM limits the application of the regulatory principles of an open Internet to the lawful nature of the contents exchanged, as well as that of the applications and equipment used, giving operators the freedom to control such violations ${ }^{22}$. It seems as if the ISPs had the ability to qualify a given content as legitimate or illegitimate, being this a matter determined in the law and discussed, on a case-by-case basis, by the competent judicial authority ${ }^{23}$. Furthermore, there is no guarantee that ISPs, even acting in good faith, exercise extreme zeal to avoid

\footnotetext{
22 "The draft rules would not prohibit broadband Internet access service providers from taking reasonable action to prevent the transfer of unlawful content, such as the unlawful distribution of copyrighted works" [25, \$16]. See also the $\$ 135$ about the proposed definition of reasonable network management.

${ }^{23}$ Lessig [41, p. 239] reminds us that even government sought "prior restraint" is not easily reached, as judges feel it is far more dangerous to free speech than a posteriori punishment.
} 
having any kind of responsibility in the commission of unlawful actions on Internet, filtering more false positives than allowing false negatives ${ }^{24}$.

For Kreimer [37], this phenomenon corresponds to what he calls "proxy censorship", the implementation of censorship measures by intermediaries due to veiled intimidation by government agents who are not constitutionally allowed to implement them. We can see this behavior in Smith v. California [56], in which a Los Angeles bookseller challeged the application of a municipal ordinance that imposed upon him criminal liability for the possesion of "obsecene or indecent" books or writings. The U.S. Supreme Court stated that the bookseller would then carry the public's burden of controlling access to obscene books. In doing so, there will be a risk of restricting access to the legal ones, because the bookseller will be as limited by the number of books he can read as enthralled by the fear of being criminally liable for those obscene he can not control. The Court concludes that " $t \mathrm{t}] \mathrm{he}$ bookseller's self-censorship, compelled by the State, would be a censorship affecting the whole public, hardly less virulent for being privately administered. Through it, the distribution of all books, both obscene and not obscene, would be impeded" [56, p. 154].

In the more recent ruling of Center for Democracy \& Technology et al. v. Pappert [59], proxy censorship was also discussed regarding the enactment by the Pennsylvania Legislature of the Internet Child Pornography Act. This Act required that after an ISP received an "informal notice" from the Pennsylvania Attorney General, it should block any child pornography material reported in this notice that could be accessible through its service. The ISPs, due to what they called "technical limitations", blocked by either URL or IP address, a clearly overbroad policy of traffic management which caused that " $[\mathrm{m}]$ ore than 1,190,000 innocent web sites were blocked in an effort to block less than 400 child pornography web sites" [59, p. 655]. The Attorney General argued that this effect was not in violation of the First Amendment, because it was the result of actions taken by the ISPs, not state actors, and moreover, the informality of the notification procedure made its acceptance a entirely voluntary action by ISPs.

\footnotetext{
${ }^{24}$ This behavior complies with the conclusions that Emerson reached on the doctrine of "prior restraint" exercised by the government [17]:

1. The scope of works that fall within a system of prior restraint is extremely broad, because as many as possible, if not all expressions subject to control, should be reviewed. The result is that, due to the volume of work, many discussions will be resolved against free expression.

2. Banned expressions never come to be communicated to anyone.

3. The decision to ban a work requires only the "stroke of a pen" on a system of prior restraint, since the onus probandi is placed on the shoulders of the affected author.

4. Because the process is administrative rather than criminal, all the guarantees necessary for due process established in the latter are not applicable.

5. Decisions made on a system of prior restraint are not usually made public, leading to the implementation of discriminatory actions that are rarely subject of public scrutiny.

6. A system of prior restraint is subject to a dynamic that drives it "toward unintelligent, overzealous and usually absurd administration."
} 
Furthermore, as the Act did not specify the means used to achieve its goals, the defendant stated that there were other options, which would not block any or as many innocent web sites, as the ISPs have done in the past.

For the Court, there were no technically and economically feasible means of blocking infringing sites beyond those based on URL or IP address, both of which were already proven to be overbroad in their application. It also found that the expectation of future technology developments that allow a more precise application of the Act, was not sufficient reason to let it to exist. The Court also concluded that the informal notices carried a language much more coercive that those found objectionable in [57], as the defendant informed the ISPs that court orders would be sought if they failed to comply. The compliance with the informal notices was anything but voluntary, according to the Court, as the "thinly veiled threats" left the ISPs with no option, turning the Informal Notice process into a tool for the "prior restraint on protected expression" [59, p. 660]. Both, the Act as well as the Informal Notice process were deemed uncontitutional, and the issue of proxy censorship of the ISPs over Internet due to legislative measures was, as Kreimer believes, definitely stablished. The reminder that the FCC made about the fact that the actions of ISPs, who are not government agents, are not directly governed by the First Amendment [25, \$75], therefore, seems to be moot due to the rulings in [56] and [59].

It seems clear that, as happened in these cases, the ISPs will prefer to apply an overbroad control over what they deem as illegal behavior over Internet, to risk being sanctioned by the State. If Internet intermediaries erect technological barriers that filter out legitimate communication, they impose exactly the censorship the government is constitutionally prohibited from sanctioning directly [37, p. 91].

The European consultation does not limit the application of the net neutrality principles to the legal contents downloaded and distributed by end users. This is justified because it is Member States and not operators who have the faculty to decide whether any given content, application or service is lawful or not $[21,(31)]$. In particular, the European legal framework considers that the service provided by operators is only of "mere conduit" [19, Arts. 1-3]. The French government has gone one step further by starting to implement measures to suppress illicit traffic on the Internet, e.g., the law known as HADOPI. The French consultative text understands that the net neutrality does not preclude the application of the law to stop unauthorized Internet behavior. Unlike the measures considered in the NPRM, the ISPs will not be free to filter content, but they will simply be responsible for implementing the decisions that the judicial authorities, based on the reports of the HADOPI, dictate.

\subsubsection{The code is the law}

In [41, chap. 14], Lessig expressed that the "code" -the software and hardware that make up Internet's skein- establishes the set of rules that governs the behavior of the internauts, clashing with the sovereignty of the national states. The State attempts to control certain behaviors through its legislation, but this legislation is of diffi- 
cult application in the cyberspace, leaving "code" to become a real law, the "law of cyberspace".

Is programmers who come to supplant the work of the legislative bodies of each nation state in creating the code [40, p. 152]. However, as Reidenberg [50, p. 566] explains, there is an analogy between what we call lex informatica (the code in the sense of Lessig) and the legal regulation. One aspect that Reidenberg points out in his work is that the primary enforcement, which in the latter is the courts who administer, is left to computers running code in an automated way in the lex informatica. Instead of a judge, an expert on the law and on the subtle balances the tradition of the law embraces, it will be a piece of code who, following an small set of very well defined rules, will state "whether and how the law would restrict your freedom" [40, p. 147].

In the NPRM, the FCC asks the Internet governance bodies, and particularly the IETF, to help it define the set of reasonable practices for traffic management and to establish protocols to help detect whether a "particular content is unlawful" [ 25 , \$141]. This situation was noted by Lessig [40, pp. 216-217], who intuited that due to pressures of the content production industry, it would be possible that States would approve rules which require that computers determine the legality of contents as well as of their distribution. By acting this way, the U.S. Government would be pushing the legal tradition aside that requires it to be a judge who takes these decisions.

This decision by the FCC, appears to signal the impotence of the State to face a complex domain such as Internet's control, by giving the ability to "legislate" to Internet governance bodies and assuming the code as a sovereignty tool. Since the set of policies to control unlawful contents comes from the Internet governance institutions, it might be possible that this kind of control extends to all Internet users, despite being only the U.S. government who requests it.

\subsubsection{Differentiated services}

The provision of differentiated services, in which operators sell access to their "fast lane" to "power buyers", could create the so-called two-tier Internet. In it, innovative services would be restricted to access the market by their ability to compete with large corporations for access to the fast lane. This goes against what has been the traditional way to enter the Internet market, and that has allowed players like Google or Facebook, to fill niches that large corporations could not. As the FCC recognizes, the ISPs may have incentives not to continue investing in the "best effort" Internet, forcing its users and content providers to use their "fast lane" services[25, \$71].

\subsubsection{Competition}

The European consultation uses as legal background, the recently ammended regulatory framework for electronic communications that relies upon competition from market forces to ensure the provision of high quality, reasonable priced communications services to the "end user" [15, p. 3]. In this sense, the preamble of $[22,(5)]$ includes the desire of European authorities that the telecommunications market be 
solely regulated by competition law, limiting the application of specific regulations to those cases "where there is no effective and sustainable competition." It seems contradictory to call a public consultation on the need for special legislation in the subject of net neutrality, when there has been virtually no need for intervention from the European competition authorities in conflicts between the actors that make the Internet possible. Even more, why consult the European ensemble on a topic that the Commission itself acknowledges has been enshrined in the Telecom Package ${ }^{25}$ "as a policy objective and regulatory principle to be promoted by national regulatory authorities"?

\section{Statistics of the consultations and their Interpretations}

There is a huge difference in the number of participants between the American and the French consultations. In total there are more than 89,000 filings in the American one, where as the French consultation was answered by only 121 stakeholders [43], The level of participation seems low for a country with close to 65 million people of which $68.9 \%$ have access to Internet [36]. What explains the huge difference in the number of answers between the US and French consultations? The next subsections partly explain the large difference.

Among the 121 stakeholders [43] in the French consultation, eight came from ISPs, four from networking vendors, six from content production corporations, three from copyright collecting societies, eleven from software and content providers, six from user associations, three from public initiative networks, four from other kinds of professional associations, two from a group of experts gathered by Nathalie Kosciusko-Morizet ${ }^{26}$, five by researchers and 67 by individual citizens.

We can compare these figures with the consultation process in Canada that was initiated by the CRCT. It provided around three months for sending comments to the commission. In addition it had several days of hearing. The commission which received " 437 initial comments, 35 reply comments, and 34 final replies from parties (companies and advocacy groups) and individuals. In addition, an online campaign resulted in over 13,000 email submissions to the Commission from individuals. At the oral hearing in July 2009, 26 presentations were made. Finally, an online consultation initiated by the Commission resulted in 1,400 additional individual comments" [ 8 , \$10]. Thus the response to the French consultation is also much lower than the one for the Canadian consultation.

\subsection{Duration and timing}

Of the three public consultation processes, the French was the shortest, running for 39 days (April 9 to May 17, 2009), followed by the European, that extends for 93 days (June 30, 2010 to September 30, 2010), and then the longest is the American, which

\footnotetext{
${ }^{25}$ See $[22$, Art. $8(4)(\mathrm{g})]$.

${ }^{26}$ State Secretary for the Digital Economy.
} 
ran for 187 days (October 22, 2009 to April 26, 2010) ${ }^{27}$. The French consultation is not only much shorter than the American. The timing for the consultation was chosen to overlap the two weeks vacation period of the Eastern holidays in France, in which many French spending vacations with their families are disconnected from the politics. Since both the duration and the timing of the consultation are under the control of the government, it seems natural to speculate that the French government was not interested in having a large participation.

\subsection{The impact of the government position}

As can be seen in the FCC web site, the vast majority of the answers to the consultation in USA came from individuals who used a web tool provided by the savetheinternet. com platform for the automation of this process. This tool had a very basic template with a short standard text in favor of net neutrality, in which the interested individual provided his name. In view of the government position, the large number of participants and, in particular, the large support for the neutralituy, are seen as a success of the government which had a clear position in favor of the net neutrality.

We recall that in France, the government did not adopt an official position but seem to have been against the net neutrality (see Section 4). The consultation could be an instrument for increasing the citizen's participation in fundamental choices for society. Probably, for the government, this could come at the cost of loosing some of its control on these issues. And indeed, as we can see from the conditions chosen to launch the consultation, the government was not interested in receiving a large number of responses.

Minimizing the dimensions of the public debate associated with the consultation may also be useful in order to avoid the French citizens questioning other aspects of the government policy on the Internet. In particular, the government was probably aware that public discussions on the HADOPI law ${ }^{28}$ could be triggered by the fact that the questionaire of the French consultation includes an important link between the HADOPI law and the proposed net neutrality.

The relatively limited interest in France in getting feedback from Internauts should not be interpreted as a dissinterest in the opinion of the various economic actors. Indeed, as we have already seen, there was a conference held by the ARCEP in which important economic actors participated ${ }^{29}$.

\footnotetext{
${ }^{27}$ Due to the "Comcast" decision[58], the FCC extended the deadline for filing reply comments in response to the NPRM from March 5 to April 26.

${ }^{28}$ Adopted in France last year and which bans downloading unauthorized copyrighted content.

${ }^{29}$ We were surprised not to see among the participants speakers from French universities or research institutes. In fact, the two only talks from Professors in universities are from the USA. In addition, one can find video interviews of many stakeholders in the conference's home page: http: / /ww . arcep. fr/index . php?id=10370.
} 


\section{Discusion and conclusions}

The evolution of the Internet all around the world has come to a point where almost at the same time, the governments felt the need for legislation to regulate access to the Internet, providing access to subscribers and rules for using the Internet. In preparing these laws, the citizens were invited to participate in determining key features of the future Internet through various consultations around the world. In all consultations, the voice of those who respond is not binding to those drafting legislation, so their answers are only seen as mere advice. Yet, the opportunity to participate in a debate on the rules for regulating the Internet may give the citizens the expectation that they are in political control of its future.

All consultations were successful in getting detailed opinions of representatives of the various economic actors. The degree of involvement of the end users, the Internauts, varied a lot between the consultations. As we saw, in the USA the government obtained a high involvement of the public, which reflects the will of the government to have the political backing. In France, in contrast, the response to the consultation was much smaller than in the USA, which we explained at the end of the paper.

By the time this paper was finished, the European consultation had been still open, so no data on participation were available. Nonetheless, this consultation overlapped with the summer holidays, a period of traditional stoppage of activities in the European continent. Thus, we believe that the timing of the consultation, as well as its duration, will result in a level of participation more similar to that in France than to the one in the USA.

\section{References}

[1] United States Code.

[2] Eitan Altman, Chadi Barakat, Pierre Bernhard, Eric Fleury, Philippe Jacquet, Arnaud Legout, Corinne Touati, Bruno Tuffin, and Sulan Wong. An answer to the french consultation over network neutrality (9th april to 17th may, 2010), 2010. http://www-sop.inria.fr/members/Eitan.Altman/nn.html.

[3] ARCEP. Neutralité des réseaux: Les actes du colloque. Technical report, 2010.

[4] S. Blake, D. Black, M. Carlson, E. Davies, Z. Wang, and W. Weiss. An architecture for differentiated services ( $r f c$ 2475). IETF, December 1998. http://www. ietf.org/rfc/rfc2475.txt.

[5] Christopher Boam. Verizon: "tous les bits ne sont pas égaux". La Lettre de L’Autorité de Régulation des Communications Électroniques et des Postes, 67:19, 2009.

[6] R. Braden, D. Clark, and S. Shenker. Integrated services in the internet architecture: an overview ( $\mathrm{rfc} 1633$ ). IETF, 6 1994. http://www . apps . ietf .org/ rfc/rfc1633.html. 
[7] Lee A. Bygrave and Terje Michaelsen. Governors of Internet. In Lee A. Bygrave and Jon Bing, editors, Internet Governance: Infrastructure and Institutions, pages 92-140. Oxford University Press, 2009.

[8] Canadian Radio-television and Telecommunications Comission. Telecom Regulatory Policy CRTC 2009-657, 2009.

[9] B. Carpenter. Architectural principles of the internet ( $\mathrm{rfc}$ 1958). IETF, June 1996. http://www. ietf.org/rfc/rfc1958.txt.

[10] Brian Carpenter and Kathleen Nichols. Differentiated services (diffserv) (concluded wg). IETF, March 29, 2002. http://datatracker . ietf .org/wg/ diffserv/charter/.

[11] Commission of the European Communities. European governance: A white paper. $\operatorname{COM}(2001) 428$ final, July 2001.

[12] Commission of the European Communities. Towards a reinforced culture of consultation and dialogue - General principles and minimum standards for consultation of interested parties by the Commission. COM(2002) 704 final, December 2002.

[13] Commission of the European Communities. Public consultation on content online in the single market, July 2006.

[14] Commission of the European Communities. Telecom reform 2009: Commission declaration on net neutrality. Official Journal of the European Communities $\mathrm{L}_{337}, 2009$.

[15] Commission of the European Communities. Questionnaire for the public consultation on the open Internet and net neutrality in Europe, June 2010.

[16] Dorgan, Snowe, Kerry, Boxer, Harki, Leahy, Clinton, Obama, and Widen. Internet freedom preservation act (s. 215), January 2007.

[17] Thomas I. Emerson. The doctrine of prior restraint. Law and Contemporary Problems, 20:648-671, 1955.

[18] José Antonio Estévez Araujo. Que no te den gobernanza por democracia. Mientras tanto, 108-109:33-49, 2008.

[19] European Parliament and Council of the European Union. Directive 2000/31/EC of the European Parliament and of the Council of 8 June 2000 on certain legal aspects of information society services, in particular electronic commerce, in the Internal Market (Directive on electronic commerce), June 2000. 
[20] European Parliament and Council of the European Union. Directive 2002/21/EC of the European Parliament and of the Council of 7 March 2002 on a common regulatory framework for electronic communications networks and services (Framework Directive), March 2002.

[21] European Parliament and Council of the European Union. Directive 2009/136/EC of the European Parliament and of the Council of 25 November 2009 amending Directive 2002/22/EC on universal service and users' rights relating to electronic communications networks and services, directive 2002/58/EC concerning the processing of personal data and the protection of privacy in the electronic communications sector and Regulation (EC) No 2006/2004 on cooperation between national authorities responsible for the enforcement of consumer protection laws, November 2009.

[22] European Parliament and Council of the European Union. Directive 2009/140/EC of the European Parliament and of the Council of 25 November 2009 amending Directives 2002/21/EC on a common regulatory framework for electronic communications networks and services, 2002/19/EC on access to, and interconnection of, electronic communications networks and associated facilities, and 2002/20/EC on the authorisation of electronic communications networks and services, November 2009.

[23] European Union. Treaty of Lisbon. Official Journal of the European Union (2007/C306/01), 2007.

[24] Federal Communications Commission. Policy Statement (FCC 05-151), August 2005.

[25] Federal Communications Commission. Notice of proposed rulemaking (FCC 09-93), October 2009.

[26] Federal Communications Commission. Order in the matter of preserving the open internet, broadband industry practices, April 2010.

[27] Federal Trade Commission. FTC to Host Workshop on Broadband Connectivity Competition Policy, December 2006. http://www.ftc.gov/opa/2006/12/ broadbandworkshop2. shtm.

[28] French Constitutional Council. Décision Nro. 2009-58o DC du 10 juin (Loi favorisant la diffusion et la protection de la création sur internet), 2009.

[29] French Republic. Consultation publique sur la neutralité du net, from 9 april to 17 may 2010.

[30] Michael Geist. Towards a two-tier Internet. BBC News, December 22, 2005. http://news.bbc.co.uk/2/hi/technology/4552138.stm. 
[31] Julius Genachowski. The third way: A narrowly tailored broadband gramework. Federal Communications Commission, May 6, 2010. http://www . broadband.gov/the-third-way-narrowly-tailored-broadbandframework-chairman-julius-genachowski.html.

[32] Gene Green and et. al. Letter to julius genachowski. Congress of the United States, May 24, 2010. http://www.policybytes.org/Blog/ PolicyBytes.nsf/dx/TitleII_FCC_24May2010.pdf/\$file/TitleII_ FCC_24May2010.pdf.

[33] D. Grossman. New terminology and clarifications for diffserv ( $\mathrm{rfc} 3260)$. IETF, April 2002. http://www. ietf .org/rfc/rfc2002.txt.

[34] Robert W. Hahn and Robert W. Litan. The myth of network neutrality and what we should do about it. International Journal of Communication, 1:596-606, 2007.

[35] Robert W. Hahn and Scott Wallsten. The economics of net neutrality. Economists' Voice, 3:1-7, 2006.

[36] Internet World Stats. Internet users in the european union, June 302010. http://www . internetworldstats . com/stats9.htm.

[37] Seth F. Kreimer. Censorship by proxy: the first amendment, Internet intermediaries, and the problem of the weakest link. University of Pennsylvania Law Review, 155:11-101, 2006-2007.

[38] Neelie Kroes. Net neutrality in Europe. RAPID Press Release, April 2010. http://europa.eu/rapid/pressReleasesAction.do? reference $=\mathrm{SPEECH} / 10 / 153$.

[39] Mark A. Lemley and Lawrence Lessig. The end of end-to-end: preserving the architecture of the Internet in the broadband era. UCLA Law Review, 48:925-972, 2000.

[40] Lawrence Lessig. Free Culture. Penguin Books, New York, 2004.

[41] Lawrence Lessig. Code: version 2.o. Basic Books, New York, 2006.

[42] Declan McCullagh. Tech companies ask for unfiltered Net. CNET News, November 18, 2002. http://news . cnet. com/2100-1023-966307.html.

[43] Ministère de l'Économie, de l'industrie et de l'emploi. Consultation publique sur la neutralité du Net. telecom.gouv.fr, June 21 2010. http://www.telecom.gouv.fr/rubriques-menu/ organisation-du-secteur/textes-reglementaires/ consultations-appels-candidatures/consultations-ouvertes/ consultation-publique-sur-neutralite-du-net-2383.html. 
[44] Arshad Mohammed. Verizon executive calls for end to google's "free lunch". The Washington Post, February 7 2006. http: //www . washingtonpost . com/ wp-dyn/content/article/2006/02/06/AR2006020601624.html.

[45] Gautham Nagesh. Kerry: Net-neutrality legislation unlikely, fcc must act. The Hill, August, 5 2010. http: //thehill.com/blogs/hillicon-valley/technology/ 112935-kerry-net-neutrality-legislation-unlikely-fcc-must-act.

[46] Nemertes Research. User demand for the internet could outpace network capacity by 2010, November 19 2007. http://www.nemertes.com/ press_releases/user_demand_internet_could_outpace_network_ capacity_2010.

[47] K. Nichols, S. Blake, F. Baker, and D. Black. Definition of the differentiated services field (ds field) in the ipv4 and ipv6 headers ( $r f c$ 2474). IETF, December 1998. http://www.ietf .org/rfc/rfc2474.txt.

[48] Patricia O'Connell. Online extra: At sbc, it's all about "scale and scope". BusinessWeek, November 7, 2005. http://www. businessweek.com/print/ magazine/content/05_45/b3958092.htm?chan=gl.

[49] Viviane Reding. Net Neutrality and Open Networks - Towards a European Approach. RAPID Press Release, September, 30 2008. http://europa.eu/ $\mathrm{rapid} / \mathrm{pressReleasesAction} \cdot$ do?reference=SPEECH/08/473.

[50] Joel R. Reidenberg. Lex informatica: The formulation of information policy rules through technology. Texas Law Review, 76(3), February 1998.

[51] J.H. Saltzer, D.P. Reed, and D.D. Clark. End-to-end arguments in system design. ACM Transactions in Computer Systems, 2:277-288, 1984.

[52] Sandvine. Taffic management in a world with network neutrality. Technical report, 2008.

[53] Nicolas Sarkozy. Voeux au monde de la culture. Élysée, Présidence de la République, January 7, 2010. http://www.elysee.fr/president/ les-actualites/discours/2010/voeux-au-monde-de-la-culture. 1618.html.

[54] Snowe, Dorgan, Inouye, Wyden, Leahy, Boxer, Obama, and Clinton. Internet freedom preservation act (s. 2917), May 2006.

[55] Lawrence B. Solum. Models of Internet governance. In Lee A. Bygrave and Jon Bing, editors, Internet Governance: Infrastructure and Institutions, pages 48-91. Oxford University Press, 2009.

[56] Supreme Court of the United States of America. Smith v. California, 361 U.S. $147,1959$. 
[57] Supreme Court of the United States of America. Bantam Books, Inc. v. Sullivan., 372 U.S. $58,1963$.

[58] United States Court of Appeals, District of Columbia Circuit. COMCAST Corporation (Petitioner) v. Federal Communications Commission and United States of America (Respondents) and NBC Universal, et al. (Intervernors), 600 F.3d 642, 2010.

[59] United States District Court, E.D. Pennsylvania. Center for Democracy \& Technology, On Behalf of Itself; American Civil Liberties Union On Behalf of Its Members; and, Plantagenet, Inc., On Behalf of Itself and Its Customers, Plaintiffs, v. Gerald J. Pappert, Attorney General of the Commonwealth of Pennsylvania, Defendant (337 F.Supp.2d 606), 2004.

[6o] Sulan Wong, Eitan Altman, and Julio Rojas-Mora. Internet access: Where law, economy, culture and technology meet. Computer Networks, special issue on Wireless Future Internet, 2010. To appear.

[61] World Summit on the Information Society. Tunis agenda for the information society. ITU, November 2005. http://www.itu.int/wsis/docs2/tunis/ off/6rev1.pdf.

[62] Tim Wu. Network neutrality, broadband discrimination. Journal of Telecommunications and High Tecnology Law, 2:141-178, 2003.

[63] Tim Wu. Controlling commerce and speech. The Wall Street Journal, August 92010 http://www.nytimes.com/ roomf ordebate/2010/8/9/who-gets-priority-on-the-web/ controlling-commerce-and-speech.

[64] Patrick Zelnik, Jacques Toubon, and Guillaume Cerutti. Creation et Internet. Technical report, Ministre de la Culture et de la Communication, République Française, 2010. http://www. culture.gouv.fr/mcc/Espace-Presse/ Dossiers-de-presse/Rapport-Creation-et-Internet. 
Centre de recherche INRIA Sophia Antipolis - Méditerranée 2004, route des Lucioles - BP 93 - 06902 Sophia Antipolis Cedex (France)

Centre de recherche INRIA Bordeaux - Sud Ouest : Domaine Universitaire - 351, cours de la Libération - 33405 Talence Cedex Centre de recherche INRIA Grenoble - Rhône-Alpes : 655, avenue de l'Europe - 38334 Montbonnot Saint-Ismier Centre de recherche INRIA Lille - Nord Europe : Parc Scientifique de la Haute Borne - 40, avenue Halley - 59650 Villeneuve d'Ascq Centre de recherche INRIA Nancy - Grand Est : LORIA, Technopôle de Nancy-Brabois - Campus scientifique 615, rue du Jardin Botanique - BP 101 - 54602 Villers-lès-Nancy Cedex

Centre de recherche INRIA Paris - Rocquencourt : Domaine de Voluceau - Rocquencourt - BP 105 - 78153 Le Chesnay Cedex

Centre de recherche INRIA Rennes - Bretagne Atlantique : IRISA, Campus universitaire de Beaulieu - 35042 Rennes Cedex Centre de recherche INRIA Saclay - Île-de-France : Parc Orsay Université - ZAC des Vignes : 4, rue Jacques Monod - 91893 Orsay Cedex 